\title{
Investigation into the Synergistic Effect of Nano-sized Materials on the Anti-corrosion Properties of a Waterborne Epoxy Coating
}

\author{
Xiaoqing Xiao ${ }^{1 * *}$, Dongmei Wang ${ }^{1 * *}$, Yongxin Li ${ }^{1,4, *}$, Emily Jackson ${ }^{4}$, Yida Fang ${ }^{4}$, Yan Zhang ${ }^{4}$, \\ Ning Xie , Xianming Shi, ${ }^{2,3,4, *}$ \\ ${ }^{1}$ College of Chemistry and Materials Science, Anhui Normal University, Wuhu 241000, China \\ ${ }^{2}$ Department of Civil \& Environmental Engineering, P. O. Box 642910, Washington State University, \\ Pullman, WA 99164-2910, USA \\ ${ }^{3}$ School of Civil Engineering and Architecture, Wuhan Polytechnic University, Wuhan, 430023, \\ China. \\ ${ }^{4}$ Western Transportation Institute, Montana State University, Bozeman, MT 59717-2220, USA. \\ *E-mail: yongli@mail.ahnu.edu.cn; xianming.shi@wsu.edu \\ ***-first authors
}

doi: $10.20964 / 2016.07 .66$

Received: 29 March 2016 / Accepted: 13 May 2016 / Published: 4 June 2016

\begin{abstract}
A kind of environmentally friendly waterborne epoxy coating incorporating several nano-sized materials, nano- $\mathrm{Fe}_{2} \mathrm{O}_{3}$, multi-wall carbon nantubes (CNTs), polysiloxane-modified montmorillonite, and non-modified montmorillonite, were successfully synthesized on the surface of steel substrates through a room-temperature curing method. Thirty-two nanocomposite coatings were formulated by varying the dosage of these four nanomaterials and a commercial corrosion inhibitor and by following a statistical design of experiments. The morphologies of the nanomaterials and cured epoxy coating or nanocomposite coatings were examined by scanning electron microscopy (SEM). The effect of incorporating nanomaterials at different ratios on the thermal property, mechanical property and anticorrosion properties of the epoxy coating was investigated by differential scanning calorimetry (DSC), microhardness test, potentiodynamic polarization and electrochemical impedance spectroscopy (EIS), respectively. The results show that adding the nanomaterials at special ratios can significantly improve the mechanical and anti-corrosion properties of the epoxy coating. In particular, the concurrent incorporation of small amounts of ZPA, nano- $\mathrm{Fe}_{2} \mathrm{O}_{3}$ and CNTs into the waterborne epoxy coating led to outstanding corrosion resistance on steel. This study sheds light on the multifunctional role of nanomaterials in modifying the microstructure and chemistry of the cured epoxy coating and in improving the coating/steel interface.
\end{abstract}


Keywords: interfaces; electrochemical techniques; coatings; electron microscopy; corrosion; Hardness

\section{FULL TEXT}

(C) 2016 The Authors. Published by ESG (www.electrochemsci.org). This article is an open access article distributed under the terms and conditions of the Creative Commons Attribution license (http://creativecommons.org/licenses/by/4.0/). 